\title{
Green Coffee Extract Blockades Haloperidol- Induced Catalepsy and Contralateral Rotations Induced by Apomorphine After Unilateral 6-OHDA Lesion on Striatum
}

\section{Graziella Molska}

Federal University of Sao Paulo

Lyvia Izaura Paula-Freire

Federal University of Sao Paulo

Marna Sakalem

Federal University of Sao Paulo

Daniele Köhn

Federal University of Sao Paulo

Giuseppina Negri

Federal University of Sao Paulo

\section{Elisaldo Carlini}

Federal University of Sao Paulo

Fúlvio Mendes ( $\square$ fulviorm@hotmail.com )

Universidade Federal do ABC

\section{Research Article}

Keywords: Coffea arabica, Parkinson's disease, 6-OHDA model, catalepsy, chlorogenic acids, caffeine, neuroprotection, antioxidant

Posted Date: December 21st, 2020

DOl: https://doi.org/10.21203/rs.3.rs-129362/v1

License: (c) (1) This work is licensed under a Creative Commons Attribution 4.0 International License. Read Full License 


\section{Abstract}

Epidemiological studies have shown an inverse association between coffee consumption and the development of Parkinson's disease (PD). The present investigation aimed to evaluate the effects of caffeine and green (non-roasted) coffee extract in experimental models of PD. The effects of the oral treatment with green coffee extracts (CE, Coffea arabica 100 or $400 \mathrm{mg} / \mathrm{kg}$ ) and caffeine $(31.2 \mathrm{mg} / \mathrm{kg}$ ) were evaluated on the catalepsy induced by haloperidol in mice and unilateral 6-OHDA lesion of medial forebrain bundle (MFB) or striatum in rats. Also, the in vitro antioxidant activity and the monoamine levels in the striatum were investigated. CE presented a mild antioxidant activity and administration decreased the catalepsy index. CE at the dose of $400 \mathrm{mg} / \mathrm{kg}$ induced ipsilateral rotations 14 days after the lesion. However, the 30-day CE and caffeine treatments did not interfere with the animals' rotation after apomorphine or methamphetamine challenges in animals with MFB lesion, nor on monoamines levels. Furthermore, CE and caffeine were effective in inhibiting the asymmetry between ipsilateral and contralateral rotations induced by methamphetamine and apomorphine in animals with lesion in the striatum but did not avoid the monoamines depletion. These results suggest a pro-dopaminergic action of $\mathrm{CE}$, although its mechanism remains unclear.

\section{Introduction}

Parkinson's disease (PD) is considered the second most common neurodegenerative disorder, with an estimated prevalence of 1 to $3 \%$ in the population over the age of 65 years, and with an increasing prevalence among older people ${ }^{1}$. PD is mainly characterized as a progressive degeneration of dopaminergic neurons in substantia nigra pars-compacta, and the presence of Lewy bodies (intraneuronal aggregates of a-synuclein and other misfolded proteins) is one of the most important neuropathological hallmarks ${ }^{2}$. Although the pathophysiology of PD is complex, several evidences have shown that the increased dopamine oxidation associated with decreased endogenous antioxidant defense are key elements in the development of the disease ${ }^{2}$.

The current medicines used in PD are able to improve the quality of life, but cannot avoid the progressive neuron degeneration, making it important to identify potential protective factors such as diet or life style that could diminish the risk of developing PD, and also, to find new drugs which could avoid the disease progression. Several observational studies and meta-analysis have shown an inverse correlation between coffee consumption and incidence of $P D$, what leads to the hypothesis that caffeine presents a protective effect on $\mathrm{PD}^{3-6}$.

Coffee is the most consumed beverage worldwide, being usually prepared by the infusion of roasted seeds of Coffea arabica L. or its varieties. The psychological effects of coffee are largely due to the presence of caffeine, which acts mainly through the adenosine receptors antagonism, more specifically as antagonist of adenosine $A_{1}$ and $A_{2 A}$ receptors ${ }^{7}$. The adenosinergic system is co-localized with dopaminergic neurons in several brain regions, in special in the basal ganglia, where it negatively modulates the dopaminergic system ${ }^{7,8}$. The blockage of adenosine $A_{2 A}$ receptors on striatal neurons has 
been suggested to explain the neuroprotective action of caffeine in $\mathrm{PD}^{8-11}$. Recently, istradefylline, a selective adenosine $A_{2 A}$ receptor antagonist, was approved by FDA as an add-on treatment of PD patients under treatment with levodopa presenting off episodes ${ }^{12}$.

Nevertheless, although the neuroprotective effect of coffee on PD is attributed mainly to caffeine, several authors emphasize the importance of polyphenols and other constituents, suggesting that they can strongly contribute to the beneficial effects of coffee, tea and other caffeinated beverages ${ }^{13,14}$. It has been previously demonstrated that the amount of chlorogenic acids and its derivatives, caffeic acid, ferulic acid, quinic acid and several flavonoids, depends on the variety of coffee, roasting process and methods of preparation ${ }^{15,16}$. Depending on the temperature and roasting time, most chlorogenic acids and other constituents are changed or decomposed, while caffeine remains almost unaffected ${ }^{15,17}$.

Chlorogenic acids (quinic esters of hydroxycinnamic acids) is a family of esters formed between quinic acid and three most common trans-cinnamic acids: caffeic acid, ferulic acid and p-coumaric acid. The main chlorogenic acids classes in green coffee are: caffeoylquinic acids, dicaffeoylquinic acids, and feruloylquinic acids ${ }^{18}$.

Currently, there is evidence of the protective role of chlorogenic acids and its derivatives in PD and Alzheimer's disease, based on both epidemiological and experimental studies ${ }^{13,14,19,20}$. Considering this, the present investigation aimed to evaluate the effects of green (non-roasted) coffee extract, rich in chlorogenic acids, in the following experimental models of Parkinson's disease: catalepsy induced by haloperidol, and rotational behavior after unilateral 6-OHDA lesion of medial forebrain bundle or striatum.

\section{Material And Methods}

\section{Extract}

The green coffee extract (CE) was produced by spray dryer technique with dry unroasted seeds of coffee (Coffea arabica $\mathrm{L}$ ) by Centroflora (Botucatu, Brazil). The extract was evaluated for its physical and chemical characteristics by IT2 100 method (standardized in $21.04 \%$ of chlorogenic acid, $27-33 \%$ of caffeoylquinic acid and $7.5 \%$ to $8 \%$ of caffeine), according to the report provided by the manufacturer.

\section{Drugs}

Apomorphine, caffeine and 6-hydroxydopamine (6-OHDA) were purchased from Sigma (St. Louis, USA) and haloperidol $\left(\right.$ Haldol $^{\circledR}$ ) from Janssen Pharmaceutica N.V. (Beerse, Belgium). Methamphetamine was donated by the Brazilian Federal Police. For HPLC analysis, caffeine standard was purchased from Fluka (Munich, Germany) and 5-O-caffeoylquinic acid standard from Sigma-Aldrich (Milano, Italy). HPLC-grade methanol was purchased from Merck (Darmstadt, Germany) and HPLC-grade water was prepared from distilled water using a Milli-Q system (Millipore, Waters, Milford, USA).

\section{Caffeine dosage}


Caffeine quantification in CE was carried out through phase reversed high-performance liquid chromatography with Diodo Array detector (HPLC/DAD). The HPLC-DAD analyses were conducted on a Hewlett Packard 1090 II equipped with a degasser, an autosampler, and diode array detector. The identification of caffeine was based on retention time, UV spectra comparison with a standard and spiking. Quantitation was obtained through a calibration curve made with known concentrations of caffeine. The calibration curve for caffeine $(Y=2935.6 \mathrm{X})$ was found to be linear with $R^{2}=0.99$.

The coffee extract was dissolved in water: methanol (80:20) v/ $\mathrm{v}(5 \mathrm{mg} / 2 \mathrm{~mL})$ and filtered with a $0.45 \mu \mathrm{m}$ polytetrafluoroethylene (PTFE) filter, prior to injection of $31.2 \mu \mathrm{L}$ into the HPLC system, using a reverse phase, C18, Spherisorb ODS II (Hewlett Packard) column $(4.6 \times 250 \mathrm{~mm}, 5 \mu \mathrm{m})$, connected to a guard column. Spectral UV data from all peaks were collected in the spectral range $240-400 \mathrm{~nm}$, and chromatograms were recorded at 330 (caffeoylquinic acid derivatives and feruloylquinic acids derivatives) and $270 \mathrm{~nm}$ (caffeine) ${ }^{21}$. The mobile phases consisted of eluent $A(0.1 \%$ aq. formic acid) and eluent $B$ (methanol), with the following gradient profile: 0 min $-20 \% B$ in $A ; 10$ min $-30 \% B$ in $A, 20$ min $50 \% \mathrm{~B}$ in $\mathrm{A} ; 30 \mathrm{~min}-70 \% \mathrm{~B}$ in $\mathrm{A} ; 40 \mathrm{~min}-90 \% \mathrm{~B}$ in $\mathrm{A} ; 45 \mathrm{~min}-40 \% \mathrm{~B}$ in $A$ and finally returned to the initial conditions ( $20 \% \mathrm{~B}$ in $\mathrm{A})$ to re-equilibrate the column prior to another run. The flow rate was kept constant at $0.8 \mathrm{~mL} / \mathrm{min}$, and the temperature of the column was maintained at $28^{\circ} \mathrm{C}$.

\section{Animals}

Male Swiss mice ( 40 to $50 \mathrm{~g}$ ) and male Wistar rats (300 to $400 \mathrm{~g}$ ) 2-5 months old were provided by the bioterium of Psychobiology from Universidade Federal de São Paulo (UNIFESP). Animals were kept in rooms with controlled temperature $\left(23 \pm 2^{\circ} \mathrm{C}\right)$ and light/dark cycle of 12 hours with water and food ad libitum. The project was approved by the Ethics Committee of UNIFESP (CEP \#1946/06) and we followed the ARRIVE guidelines principles of the use of laboratory animals.

\section{Animals' treatment}

CE (doses of 100 and $400 \mathrm{mg} / \mathrm{kg}$ ) and caffeine $(31.2 \mathrm{mg} / \mathrm{kg}$ - the equivalent caffeine in $400 \mathrm{mg} / \mathrm{kg}$ of $\mathrm{CE}$ ) were solubilized in water and orally administered by gavage in the volume of $1 \mathrm{~mL} / \mathrm{kg}$ (rats) and 10 $\mathrm{mL} / \mathrm{kg}$ (mice). The control animals received the vehicle water at the same volume by gavage.

\section{Evaluation of antioxidant capacity}

Antioxidant activity was evaluated by the lipid peroxidation inhibition measured by malondialdehyde concentration in rat brain homogenate. Tissue homogenate was prepared with phosphate buffer and centrifuged at $3000 \mathrm{rpm}$ for 15 minutes. The supernatant was collected and then diluted again in phosphate buffer (1:3). Five concentrations of CE were added to each homogenate tube as follows: 4.17 $\mu \mathrm{g} / \mathrm{mL} ; 8.33 \mu \mathrm{g} / \mathrm{mL} ; 12.50 \mu \mathrm{g} / \mathrm{mL} ; 16.67 \mu \mathrm{g} / \mathrm{mL} ; 33.33 \mu \mathrm{g} / \mathrm{mL}$ (final concentrations), and then incubated in water bath with thiobarbituric acid for 60 minutes at $37^{\circ} \mathrm{C}$. The experiment was carried out according to the methodology described by Stocks et al. ${ }^{22}$. The antioxidant activity was determined for each concentration of the extract and the concentration inhibiting $50 \%$ of lipid peroxidation $\left(Q_{1 / 2}\right)$ was 
calculated by linear regression using the log of the concentration and the percentage of inhibition (mean of 4 assays).

\section{Catalepsy induced by haloperidol}

Groups of 10-13 mice were acutely or for 15 consecutive days treated by gavage with vehicle (controls), CE at doses of 100 or $400 \mathrm{mg} / \mathrm{kg}$ (experimental groups) or caffeine at dose of $31.2 \mathrm{mg} / \mathrm{kg}$ (positive control). Thirty minutes after the acute or the last administration of $C E$, caffeine or vehicle, the animals received haloperidol (5 mg/kg, ip), except the negative control group, which received saline (ip).

Forty-five minutes after the administration of haloperidol (or saline) the animals were placed with their forepaws positioned on a bar suspended $5 \mathrm{~cm}$ above the bench and the catalepsy time (immobility) was recorded ${ }^{23}$. The number of times each animal got off the bar over 10 minutes was recorded with a maximum of 10 times. The catalepsy index was calculated by the rate between the total catalepsy time and the number of times the mice left the bar.

\section{Unilateral lesion induced by 6-OHDA}

\section{Surgery procedure}

Male Wistar rats were anesthetized with ketamine (90 mg/kg, ip) and xylazine (5 mg/kg, ip) and placed on a stereotaxic apparatus. After the skin incision and the skull exposition, a hole was performed to the bone using a dentist drill and the neurotoxin 6-OHDA ( $12 \mu \mathrm{g} / 2 \mu \mathrm{l}$ buffered saline in $0.2 \%$ ascorbic acid) was infused with an injection pump ${ }^{24}$ in the medial forebrain bundle (MFB) of the right hemisphere (experiment 1) or in the right striatum (experiment 2) in the lesioned group, while sham-operated animals were infused with $2 \mu \mathrm{l}$ of buffered saline. The coordinates for MFB lesion were: AP, -1.9 mm; ML, -1.9 mm; DV, $-7.2 \mathrm{~mm}$ of bregma; and for striatum: AP, $+0.5 \mathrm{~mm} ; \mathrm{ML},-2.5 \mathrm{~mm}$; DV $-4.5 \mathrm{~mm}$; according to the brain atlas Paxinos and Watson ${ }^{25}$. After surgery, dental wax was applied on the skull to close the access hole, the head skin was sutured, and the animals were allowed to recover in individual boxes with food, water and controlled temperature. The experimental design of experiments 1 and 2 is shown on Fig. 1. A pilot study showed that the lesion was effective in inducing neuronal loss in the substantia nigra (Fig. 1 qualitative analysis).

\section{Experiment 1A: Effect of acute treatment with CE on the rotational behavior of rats with lesion on MFB}

Groups of 10-15 rats lesioned on MFB with 6-OHDA were challenged acutely on the $14^{\text {th }}$ day with CE (100 or $400 \mathrm{mg} / \mathrm{kg})$, caffeine $(31.2 \mathrm{mg} / \mathrm{kg})$ or vehicle by gavage. An extra group of rats that received buffered saline instead of 6-OHDA (sham-operated group) was challenged with CE $(400 \mathrm{mg} / \mathrm{kg})$ on the $14^{\text {th }}$ day. Immediately after the respective treatments, the animals were evaluated for 60 minutes and the number of contralateral and ipsilateral complete rotations $\left(360^{\circ}\right)$ in a cylinder was recorded ${ }^{26}$. On the $15^{\text {th }}$ day, all animals received apomorphine $(0.1 \mathrm{mg} / \mathrm{kg}, \mathrm{sc})$, and on the $16^{\text {th }}$ day, methamphetamine $(2.5 \mathrm{mg} / \mathrm{kg}, \mathrm{ip})$, and the number of ipsilateral and contralateral rotations was recorded again. 
Experiment 1B: Effect of repeated treatment with CE on the rotational behavior of rats with lesion on MFB

For this experiment, groups of 12-15 rats lesioned on MFB were orally treated for 30 days with CE (100 or $400 \mathrm{mg} / \mathrm{kg})$, caffeine (31.2 mg/kg) or vehicle, by gavage. An extra group of sham-operated rats received vehicle by gavage for the same period. On the $15^{\text {th }}$ and $29^{\text {th }}$ days after surgery the animals were evaluated for 60 minutes regarding the number of ipsilateral or contralateral rotations, after administration of apomorphine $(0.1 \mathrm{mg} / \mathrm{kg}, \mathrm{sc})$. On $16^{\text {th }}$ and $30^{\text {th }}$ days, methamphetamine $(2.5 \mathrm{mg} / \mathrm{kg}$, ip) was administered and the number of rotations was once again recorded.

\section{Experiment 2: Effect of pre-and post-treatment with CE on the rotational behavior of rats with striatal lesion}

Groups of $11-15$ rats were pre-treated for 15 days with CE (100 or $400 \mathrm{mg} / \mathrm{kg})$, caffeine $(31.2 \mathrm{mg} / \mathrm{kg})$ or vehicle by gavage. One hour after treatment on day 15 the rats were submitted to the stereotaxic surgery and 6-OHDA (lesioned group) or buffered saline (sham-operated group) was administered into the right striatum. The treatment continued for another 15 days and the animals were challenged with apomorphine ( $15^{\text {th }}$ day after surgery) and methamphetamine $\left(16^{\text {th }}\right.$ day) as previously described. The treatment with CE or caffeine on the days of rotational tests was made after the behavioral evaluation to avoid acute interference with apomorphine or methamphetamine.

\section{Central monoamines dosage by HPLC}

After 24 hours of the last behavioral evaluation, the animals from experiments $1 \mathrm{~B}$ and 2 were euthanized for brain collection, and the brains were frozen at $-80^{\circ} \mathrm{C}$. Later, the right (lesioned) and left (control) striatum were dissected, weighed, homogenized, centrifuged and then filtered in nitrocellulose membrane as described by Machado et al. ${ }^{27}$. Precipitates were diluted in a solution of $0.1 \mathrm{~N}$ of sodium hydroxide and evaluated for protein concentration using a colorimetric quantification kit (Pierce Chemical, Rockford, USA) and supernatants $(20 \mu \mathrm{L})$ were used for monoamines quantification through high-performance liquid chromatography (HPLC) according to method described in details by Machado et al. ${ }^{27}$. Each sample was analyzed in duplicate for concentrations of dopamine (DA), noradrenaline (NE), serotonin (5$\mathrm{HT}$ ) and their metabolites dihydroxyphenylacetic acid (DOPAC), homovanillic acid (HVA) and 5hydroxyindolacetic acid (5-HIAA). The recovery rate of the analytes was determined by adding a predetermined amount of internal standard dihydroxybenzylamine for the homogenization of tissue. The peak areas of samples were compared with peak areas of standards of each neurotransmitter or metabolite, which were injected at known concentrations, at intervals between runs.

\section{Statistical analysis}

Statistical comparisons were performed using GraphPad Prism 8.3 software. After checking for normality distribution using Shapiro-Wilks test, Kruskal-Wallis test followed by Mann-Whitney was applied to analyze the results of rotational behavior test along with Wilcoxon to compare ipsilateral and contralateral rotations among each group. Monoamines levels were analyzed using Kruskal-Wallis test 
and One-way ANOVA followed by Tukey to analyze the catalepsy. The results are expressed as mean \pm standard error (SEM) and the raw data is available in the Supplementary Data S1. Statistical significance was considered at $p<0.05$.

\section{Results}

\section{Caffeine dosage}

Chlorogenic acids are a family of esters formed between quinic acid and trans-cinnamic acids, such as caffeic, $p$-coumaric and ferulic acid, all of which can be esterified at one or more of the hydroxyls at positions 1, 3, 4, and 5 of quinic acid to generate a series of positional isomers. In RPHPLC, the isomers of the monocaffeoylquinic acids elute in the order of $3-, 5-$, and 4 -isomer and for dicaffeoylquinic acids, the elution order is 3,4-isomer, 3,5-isomer, and, finally, 4,5-isomer ${ }^{18}$.

The main constituents found in the CE are listed in the Supplementary Data S2, together with their retention times and maximum absorption wavelength observed in their respective ultraviolet spectrum ${ }^{28}$. Caffeoylquinic acid and feruloylquinic acid derivatives exhibited a UV/vis maximum wavelength absorption between 310 and $330 \mathrm{~nm}$ (band I) and a shoulder between 290 and $300 \mathrm{~nm}$ (band II), while caffeine exhibited a UV/vis maximum wavelength absorption at $272 \mathrm{~nm}^{17}$. Caffeine was the main constituent detected at a wavelength of $272 \mathrm{~nm}$ with the retention time of 22.18 minutes, in which the percentage area corresponded to $36 \%$. Through the calibration curve, the caffeine content was calculated as $7.8 \%$.

Caffeoylquinic acid and feruloylquinic acid derivatives were the main constituents detected at a wavelength of $330 \mathrm{~nm}$, but caffeine is hardly detectable due to its low absorption at $\lambda=330 \mathrm{~nm}$. Caffeoylquinic acid derivatives were the main constituent detected at a wavelength of $330 \mathrm{~nm}$, at $18.19-$ 19.44 minutes and exhibited a percentage area corresponding to 69\% (Supplementary Data S2).

\section{Evaluation of antioxidant capacity}

The percentage of inhibition of the spontaneous lipid peroxidation in rat brain homogenate for the different concentrations of $C E$ is shown in Fig. 2. The value of $Q_{1 / 2}$ obtained by linear regression from 4 assays was $8.73 \mu \mathrm{g} / \mathrm{mL}$.

\section{Catalepsy induced by haloperidol}

Haloperidol ( $5 \mathrm{mg} / \mathrm{kg}$, ip) induced catalepsy on the vehicle control group when compared to the negative control group (Fig. 3), demonstrating that the drug was effective in producing dopaminergic blockade, as expected. The acute administration of caffeine and CE $(100 \mathrm{mg} / \mathrm{kg})$ decreased the catalepsy index (Fig. 3a) when compared to the vehicle group after haloperidol injection ( $\mathrm{F}=5.127 ; p=0.0013$ followed by Tukey $p=0.0097$ for caffeine and $p=0.0455$ for CE $100 \mathrm{mg} / \mathrm{kg}$ ). Also, the administration for 15 days with CE (100 
and $400 \mathrm{mg} / \mathrm{kg}$ ) decreased the catalepsy index in comparison to the vehicle group ( $\mathrm{F}=6.923 ; p=0.0010$ followed by Tukey $p=0.0020$ for CE100 and $p=0.0262$ for CE $400 \mathrm{mg} / \mathrm{kg}$ ) (Fig. 3b).

\section{Unilateral lesion induced by 6-OHDA}

\section{Experiment 1A: Effect of acute treatment with CE on the rotational behavior of rats with lesion on MFB}

Rats with unilateral lesion on MFB were acutely challenged with vehicle, caffeine or CE ( $14^{\text {th }}$ day), apomorphine ( $15^{\text {th }}$ day), and methamphetamine ( $16^{\text {th }}$ day). The challenge with caffeine and CE 400 $\mathrm{mg} / \mathrm{kg}$ increased the number of ipsilateral rotations on lesioned rats, compared with lesioned rats treated with vehicle $(\mathrm{H}=15.104 ; p=0.004$ followed by Mann-Whitney $p=0.0218$ for caffeine and $p=0.0145$ for $\mathrm{CE}$ $400 \mathrm{mg} / \mathrm{kg}$ ), but it did not alter the number of contralateral rotations, as shown in Fig. 4a. There was significant difference between the number of contralateral and ipsilateral rotations in the group's caffeine (Wilcoxon, $p=0.0078$ ) but not in the other groups.

The lesion induced by 6-OHDA was effective in inducing contralateral rotations after apomorphine $(\mathrm{U}=811 ; p<0.0001)$ or ipsilateral rotations after methamphetamine $(U=624.5 ; p<0.0001)$ administration when compared to sham-operated group, as can be observed in Fig. $4 \mathrm{~b}$ and Fig. 4c, respectively.

\section{Experiment 1B: Effect of repeated treatment with CE on the rotational behavior of rats with lesion on MFB}

The effect of repeated treatment with CE on the rotational behavior of rats with right lesion of MFB was evaluated after challenge with apomorphine $\left(15^{\text {th }}\right.$ and $29^{\text {th }}$ days $)$ and methamphetamine $\left(16^{\text {th }}\right.$ and $30^{\text {rd }}$ days). Fig. 5 a shows that apomorphine induced contralateral rotations in all MFB experimental lesioned groups when compared to sham-operated group on $15^{\text {th }}$ day $(\mathrm{H}=22.545 ; p=0.0002$ followed by MannWhitney $p<0.05)$. The same result was observed at ipsilateral rotations induced by methamphetamine on $16^{\text {th }}$ day $(\mathrm{H}=22.280 ; p=0.0002$ followed by Mann-Whitney $p<0.05)$ (Fig. 5b). However, neither CE nor caffeine treatment changed the rotational behavior when compared with vehicle control group both after apomorphine and methamphetamine challenge $(p>0.05)$. Similar results were observed on the $29^{\text {th }}$ day with apomorphine (Fig. 5c) and $30^{\text {rd }}$ day with methamphetamine (Fig. $5 \mathrm{~d}$ ) and these results were not altered by CE or caffeine treatment $(p>0.05)$.

\section{Experiment 2: Effect of pre-and post-treatment with CE on the rotational behavior of rats with striatal lesion}

Rats were pre-treated with CE or caffeine for 15 days before the surgery and then for more 15 days after striatal lesion, prior the rotational evaluation. Typical rotations were observed after apomorphine (0.1 $\mathrm{mg} / \mathrm{kg}, \mathrm{sc}$ ) or methamphetamine (2.5 mg/kg, ip) administration on vehicle control rats with striatal lesion, although the statistical analysis has not shown differences when compared with sham-operated group, due to the great variability observed (Fig. 6a and Fig. 6b). On the other hand, statistical difference was observed between ipsilateral and contralateral rotation for the vehicle control group challenged with apomorphine (Wilcoxon $p=0.0151$ ). Also, the number of ipsilateral rotations was more than twice that of 
contralateral rotations for the vehicle control group, but the values were not statistically significant (Wilcoxon $p=0.2136$ ).

Lesioned rats treated with CE or caffeine did not differ from the sham-operated group as the number of rotations and there was no difference between contralateral and ipsilateral rotations on intra-group comparison (Fig. 6a and Fig. 6b).

\section{Central monoamines dosage by HPLC}

Table 1 shows the monoamine levels measured on the right and the left striatum of animals with MFB lesion and non-lesioned rats (sham-operated group). There is an apparent decrease of DA, NE, 5-HT and some of their metabolites on vehicle lesioned group when compared to sham-operated group on right striatum, but the values were not statistically significant $(p>0.05)$. Nevertheless, the treatments with CE or caffeine did not change the levels of monoamines. No significant effects were observed on the left (nonlesioned) side.

Table 2 shows the quantification of monoamines in the right (lesioned) and left (control) striatum of rats with striatal lesion and sham-operated animals. No significant changes $(p>0.05)$ were observed regarding quantification of neurotransmitters or their metabolites in both hemispheres (comparison among groups).

\section{Discussion}

Epidemiological studies have shown an inverse correlation between regular coffee intake and development of Parkinson's disease ${ }^{3,4,6,29}$. Experimental studies support the neuroprotective effect of caffeine through its adenosinergic antagonism ${ }^{11,30,31}$ and also suggest that other mechanisms might contribute to this protective action, such as the anti-inflammatory effect, inhibition of a-synuclein aggregation and modulation of other pathways ${ }^{32-34}$.

It is known that antioxidant compounds can potentially decrease the progression of neurodegenerative diseases such as Alzheimer's disease and PD, in which oxidative stress participates in the induction of cell death process ${ }^{35,36}$. The phytochemical analysis confirmed that the green coffee extract employed in the current study is rich in chlorogenic acids (caffeoylquinic acid and feruloylquinic acid derivatives). The content of caffeine was calculated in $7.8 \%$ and used to define the dose of caffeine group in the behavioral tests.

The antioxidant activity of the green CE was confirmed in our study using rat brain homogenates by the lipid peroxidation assay. Previous studies compared the antioxidant capacity of green and roasted coffee in different tests. The literature is controversial about the effect of roasting process on the antioxidant capacity of coffee, but some studies suggest that melanoidins and other compounds formed during the roasting also present elevated antioxidant capacity ${ }^{15,16,34,37,38}$. Daglia et al. ${ }^{38}$ showed that green coffee presented higher antioxidant activity on beta-carotene-linoleic acid in vitro assay, while roasted coffee was more potent on lipid peroxidation assay. This divergence could be explained by the difference in the 
species or varieties of coffee, the type of extract, preparation method, roasting time and methodologies used to evaluate the antioxidant activity.

PD is characterized primordially as a motor dysfunction, and catalepsy and akinesia induced by haloperidol have been used as animal models of PD and to study pro- and anti-dopaminergic drugs. MooPuc et al. ${ }^{39}$ observed an anticataleptic effect in rats treated with low doses of caffeine and suggested that caffeine could be an adjunctive therapy to reduce the doses of anticholinergics drugs in PD. Another study showed that chronic consumption of caffeine on drinking water for 6 months produced perdurable resistance to catalepsy induced by haloperidol in rats ${ }^{40}$. Selective adenosine $A_{2}$ antagonists are able to reduce the effect of haloperidol confirming the antagonistic interaction between adenosine $A_{2 A}$ and dopamine $D_{2}$ receptors and suggesting the involvement of adenosine $A_{2}$ receptors in the mechanisms of catalepsy ${ }^{41}$. The green CE used in our study probably exerts an indirect action on the dopaminergic system, demonstrated by inhibition of haloperidol-induced catalepsy, which was more evident after repeated treatment for 15 days with CE at $400 \mathrm{mg} / \mathrm{kg}$. Such result, combined with experimental studies of caffeine and other coffee components as neuroprotective agents ${ }^{11,30,31,42-44}$ support the assumption of beneficial effect of coffee on PD. To evaluate this hypothesis, we produced unilateral lesion on nigrostriatal dopaminergic pathway by injection of 6-OHDA neurotoxin in MFB and striatum.

The rotational behavior model after unilateral lesion with 6-OHDA is one of the most used animal models to study PD and drugs with potential neuroprotective effect ${ }^{26,45,46}$. The unilateral lesion leads to unbalance of dopaminergic neurotransmission between left and right striatum which can be evaluated after challenge with dopaminergic drugs, such as apomorphine and amphetamine. Our data indicate that lesioned animals had the expected rotational behavior when challenged with apomorphine and methamphetamine, in accordance with data from literature $24,47,48$. The fact that animals challenged with CE presented ipsilateral rotations provides evidence of its action on the dopaminergic system, indicating an effect similar to methamphetamine, an indirect agonist. Cauli et al. ${ }^{49}$ showed that the administrations of caffeine for two weeks could increase dopamine release in the intact side of the striatum, consistent with the ipsilateral direction of the rotational behavior. Moreover, it has been shown that caffeine does not bind to dopamine receptors, suggesting that this action has occurred by indirect mechanism, such as adenosinergic modulation. Furthermore, other coffee constituents would also be responsible for the observed effect.

The effects of the repeated treatment with CE before the challenge with apomorphine and methamphetamine were also analyzed. The treatment started 24 hours after the MFB injury with 6-OHDA and the animals were treated for 30 days with the objective of evaluating whether the treatments could exert a neuroprotective effect and avoid the asymmetry on the rotational test. There was no difference in the type and number of rotations among different experimental groups, including the caffeine group. This result does not corroborate with a previous study in which caffeine $(15 \mathrm{mg} / \mathrm{kg}$, ip) given acutely partially prevented the impairment of contralateral forepaw stepping in rats with MFB unilateral lesion induced by $6-\mathrm{OHDA}^{50}$. These authors also found a similar effect after acute injection of caffeine at dorsal striatum 
and external globus pallidus (20-40 $\mu \mathrm{g})$, but in both studies the authors evaluated only the behavioral response 20 minutes before the test, while the lesion itself was not quantified. Bové et al. ${ }^{51}$ discuss that the dose and number of sites of 6-OHDA may produce different effects, making difficult to compare studies using different protocols. The route of administration, dose and time of treatment with the experimental drug are also fundamental to achieve the drug efficacy.

We also evaluated the effect of CE and caffeine in the rotational behavior of rats with 6-OHDA unilateral lesion in the striatum. The animals from the control lesioned-group presented a suggestive increase in the contralateral and ipsilateral rotations (after apomorphine and methamphetamine challenge, respectively) compared to sham-operated group, although the statistical analysis did not indicate significant differences. The intra-group comparison showed that the vehicle control group presented difference between ipsilateral and contralateral rotations after apomorphine challenge. On the other hand, the rats treated with CE or caffeine showed behavior similar to those of sham-operated group, where the number of ipsilateral and contralateral rotations was equivalent. This data may suggest that the treatment was able to compensate the unbalance between right and left striatum by indirect mechanisms, which would indicate some level of neuroprotection. This result is in agreement with Machado-Filho et al. ${ }^{32}$ which employed the same experimental model and observed that caffeine $(10-20 \mathrm{mg} / \mathrm{kg}$ ) given orally for two weeks moderately reduced the contralateral rotations induced by apomorphine. The content of caffeine in our study was 7.8 and $31.2 \mathrm{mg} / \mathrm{kg}$ in CE 100 and CE $400 \mathrm{mg} / \mathrm{kg}$, respectively. The neuroprotective effect of caffeine was also observed in studies using the neurotoxin 1-methyl-4-phenyl-1,2,3,6-tetrahydropyridine $(\text { MPTP })^{30,31}$.

The contents of monoamines and their metabolites were measured in the left and right striatum of the rats with lesion on right MFB (study 1 ) and right striatum (study 2). In the first study the levels of DA and NE were moderately reduced in the lesioned side in the vehicle-control group when compared to the shamoperated group (decrease of 52.1 and $44.5 \%$, respectively), although the difference was not significant. However, the levels of neurotransmitters or metabolites of rats treated with CE and caffeine did not differ from the vehicle control group. This suggest that the treatment was not efficient in protecting nigrostriatal neurons from 6-OHDA.

Regarding the second experiment, the levels of DA, NE, 5-HT and its metabolites seemed decreased on lesioned control group (vehicle) in comparison with the sham-operated group, but there was no significant difference. The levels of DA and NE were reduced in 59.1 and 61.3\%, respectively. Moreover, the experimental groups treated with CE or caffeine showed levels of neurotransmitters and metabolites similar to the vehicle, indicating that the treatments did not prevent the reduction of monoamines in the lesioned striatum. This result is in contrast with the behavioral data, but it may suggest that the effect of $\mathrm{CE}$ and caffeine on the rotational behavior is not dependent on the dopamine level and neuronal integrity. The decrease of NE levels in both experiments may be explained because we did not give a preadministration of desipramine or other NE transporter inhibitor to the animals ${ }^{24}$. As result, our protocol allowed the uptake of 6-OHDA neurotoxin both by dopaminergic and by noradrenergic neurons causing non selective oxidative stress and neuronal death of catecholaminergic neurons. This protocol 
reproduces an advanced stage of PD in which there is pronounced loss of NA neurons, but it has the disadvantage of producing some interference in the behavioral tests.

Several studies have showed that caffeine is able to reduce the contralateral rotations induced by apomorphine, the lesion size and can attenuate the dopamine depletion after 6-OHDA injury 10,11,32,50 and can protect the neuronal loss induced by MPTP or other neurotoxins ${ }^{30,31,52}$. Other substances present in green coffee were also evaluated on different cellular and animal models of PD. The chlorogenic acid protected PC12 cells against a-synuclein ${ }^{42}$ and several coffee compounds exerted positive effects in cell culture ${ }^{20}$. Yan et al. ${ }^{44}$ evaluated the effect of low doses of caffeine and eicosanoyl-5-hydroxytryptamide (EHT) in two PD models: transgenic mice expressing human a-synuclein and striatal injection of asynuclein pre-formed fibrils in mice. The combination of the two components for 6 months was effective in normalizing the biochemical and histological parameters analyzed and in promoting improvement in behavioral tasks, while caffeine or EHT alone were ineffective or produced only moderated results ${ }^{44}$. In another study, the EHT showed protective effect against the toxin MPTP in vivo and MPP ${ }^{+}$in vitro ${ }^{43}$. The treatment with caffeic acid partially inhibited the inflammatory process in mice that received MPTP, evaluated by the level and expression of pro-inflammatory cytokines ${ }^{53}$. Other studies employing decaffeinated coffee extracts also observed protective effects in cell culture and animal models, in agreement with the hypothesis that other compounds are relevant and occasionally more important than caffeine on the coffee beneficial effects ${ }^{34,54,55}$. Based on the literature and in our results we propose that caffeine and other coffee compounds could act in different targets modulating the dopaminergic neurotransmission and motor function.

An important limitation of our study is that we did not quantify the extension and severity of the lesion induced by $6-\mathrm{OHDA}$ regarding the neuronal death. The neuronal loss on substantia nigra was qualitatively confirmed for rats from experiment 1 , which brains were sectioned and submitted to cresyl violet staining (Fig. 1). This data confirms that the protocol produced neuronal death in substantia nigra, but it is not enough to evaluate the coffee effect. In experiments 1B and 2, we measured the levels of monoamine and their metabolites in the striatum as an indirect measure of neuronal death. Despite the high variability found (see Supplementary Data S1), it was evident that the lesion protocol produced marked reduction in the levels of dopamine in the striatum of the lesioned hemisphere in control animals and CE was not able to avoid the reduction of dopamine level. Also, the lack of statistical difference in the rotational behavior and monoamine dosages among the experimental groups contrast to the observational data obtained. Deumens et al. ${ }^{56}$ argue that one of the limitations on 6-OHDA lesion model is the great variability observed among the lesioned animals, what makes it difficult to find statistical differences. The rotation model induced by unilateral lesion with neurotoxins, although widely used, have a certain complexity regarding the effects observed. Different and even opposite results may be observed depending on the neurotoxin used, the local of injury, and the extent of neuronal death ${ }^{45}$. Future studies should investigate the effect of green extract and its isolated components on lesion size after 6-OHDA or other neurotoxins employing different concentrations of extract and toxin and exploring different pathways. 
The results found in our study are in line with the hypothesis that CE components were able to modulate the dopaminergic transmission by indirect pathway, observed by the inhibition of haloperidol induced catalepsy in mice and blockade of contralateral rotation after apomorphine challenge in rats with unilateral lesion of striatum. Taken together, our results suggest a pro-dopaminergic action of the $\mathrm{CE}$, but its mechanism remains unclear and insufficient to predict whether unroasted coffee would indeed have a neuroprotective effect on PD.

\section{Declarations}

\section{Acknowledgement}

The authors are grateful to Fundação de Amparo a Pesquisa do Estado de São Paulo (FAPESP \#06/58692-1) and Associação Fundo de Incentivo à Pesquisa (AFIP) for financial support and to Dr. Ricardo B. Machado for helpful assistance in the brain monoamine analysis.

\section{Additional information}

\section{Authors' contributions}

GRM, LIGPF, and MES contributed to the acquisition, analysis and interpretation of data, draft and revising the manuscript. DOK contributed to English translation and draft and revising the manuscript. GN contributed to the caffeine quantification, analysis and interpretation of data, draft and revising the manuscript. EAC and FRM contributed to the conception and design, analysis an interpretation of data, draft and revising the manuscript. The authors declare that all data were generated in-house and that no paper mill was used. All authors reviewed and approved the content of the manuscript.

\section{Competing interests}

The authors declare no competing interests.

\section{References}

1. Del Rey, N. L. G. et al. Advances in parkinson's disease: 200 years later. Front. Neuroanat. 12, 1-14 (2018).

2. Maiti, P., Manna, J., Dunbar, G. L., Maiti, P. \& Dunbar, G. L. Current understanding of the molecular mechanisms in Parkinson's disease: Targets for potential treatments. Transl. Neurodegener. 6, 1-35 (2017).

3. Ross, G. W. et al. Association of coffee and caffeine intake with the risk of Parkinson disease. J. Am. Med. Assoc. 283, 2674-2679 (2000).

4. Hu, G., Bidel, S., Jousilahti, P., Antikainen, R. \& Tuomilehto, J. Coffee and tea consumption and the risk of Parkinson's disease. Mov. Disord. 22, 2242-2248 (2007). 
5. Sääksjärvi, K. et al. Prospective study of coffee consumption and risk of Parkinson's disease. Eur. J. Clin. Nutr. 62, 908-915 (2008).

6. Qi, H. \& Li, S. Dose-response meta-analysis on coffee, tea and caffeine consumption with risk of Parkinson's disease. Geriatr. Gerontol. Int. 14, 430-439 (2014).

7. Tóth, A., Antal, Z., Bereczki, D. \& Sperlágh, B. Purinergic Signalling in Parkinson's Disease: A Multitarget System to Combat Neurodegeneration. Neurochem. Res. (2019) doi:10.1007/s11064-01902798-1.

8. Chen, J. F. \& Chern, Y. Impacts of methylxanthines and adenosine receptors on neurodegeneration: Human and experimental studies. Handbook of Experimental Pharmacology (2011) doi:10.1007/978-3-642-13443-2_10.

9. Kalda, A., Yu, L., Oztas, E. \& Chen, J. F. Novel neuroprotection by caffeine and adenosine A2A receptor antagonists in animal models of Parkinson's disease. J. Neurol. Sci. 248, 9-15 (2006).

10. Bata-García, J. L. et al. Sustained improvement of motor function in hemiparkinsonian rats chronically treated with low doses of caffeine or trihexyphenidyl. Pharmacol. Biochem. Behav. 86, 68-78 (2007).

11. Kelsey, J. E., Langelier, N. A., Oriel, B. S. \& Reedy, C. The effects of systemic, intrastriatal, and intrapallidal injections of caffeine and systemic injections of A2A and A1 antagonists on forepaw stepping in the unilateral 6-OHDA-lesioned rat. Psychopharmacology (Berl). 201, 529-539 (2009).

12. Chen, J. F. \& Cunha, R. A. The belated US FDA approval of the adenosine A2A receptor antagonist istradefylline for treatment of Parkinson's disease. Purinergic Signalling (2020) doi:10.1007/s11302020-09694-2.

13. Heitman, E. \& Ingram, D. K. Cognitive and neuroprotective effects of chlorogenic acid. Nutr. Neurosci. 20, 32-39 (2017).

14. Zhou et al. The Therapeutic Implications of Tea Polyphenols Against Dopamine (DA) Neuron Degeneration in Parkinson's Disease (PD). Cells (2019) doi:10.3390/cells8080911.

15. Priftis, A. et al. Comparison of antioxidant activity between green and roasted coffee beans using molecular methods. Mol. Med. Rep. 12, 7293-7302 (2015).

16. Wolska, J. et al. Levels of Antioxidant Activity and Fluoride Content in Coffee Infusions of Arabica, Robusta and Green Coffee Beans in According to their Brewing Methods. Biol. Trace Elem. Res. (2017) doi:10.1007/s12011-017-0963-9.

17. Hečimović, I., Belščak-Cvitanović, A., Horžić, D. \& Komes, D. Comparative study of polyphenols and caffeine in different coffee varieties affected by the degree of roasting. Food Chem. 129, 991-1000 (2011).

18. Monteiro, M. C. \& Farah, A. Chlorogenic acids in Brazilian Coffea arabica cultivars from various consecutive crops. Food Chem. 134, 611-614 (2012).

19. Cropley, V. et al. Does coffee enriched with chlorogenic acids improve mood and cognition after acute administration in healthy elderly? A pilot study. Psychopharmacology (Berl). 219, 737-749 (2012). 
20. Taram, F., Winter, A. N. \& Linseman, D. A. Neuroprotection comparison of chlorogenic acid and its metabolites against mechanistically distinct cell death-inducing agents in cultured cerebellar granule neurons. Brain Res. (2016) doi:10.1016/j.brainres.2016.07.028.

21. Navarra, G. et al. Simultaneous determination of caffeine and chlorogenic acids in green coffee by UV/Vis spectroscopy. J. Chem. 2017, (2017).

22. Stocks, J., Gutteridge, J. M. C., Sharp, R. J. \& Dormandy, T. L. Assay using brain homogenate for measuring the antioxidant activity of biological fluids. Clin. Sci. Mol. Med. (1974) doi:10.1042/cs0470215.

23. Rodrigues, E., Gianfratti, B., Tabach, R., Negri, G. \& Mendes, F. R. Preliminary investigation of the central nervous system effects of 'Tira-capeta' (Removing the Devil), a cigarette used by some Quilombolas living in pantanal wetlands of Brazil. Phyther. Res. (2008) doi:10.1002/ptr.2474.

24. Da Cunha, C. et al. Hemiparkinsonian rats rotate toward the side with the weaker dopaminergic neurotransmission. Behav. Brain Res. 189, 364-372 (2008).

25. Paxinos, G. \& Watson, C. The Rat Brain in Stereotaxic Coordinates, 5th edition. Journal of Chemical Information and Modeling (2004). doi:10.1017/CB09781107415324.004.

26. Ungerstedt, U. \& Arbuthnott, G. W. Quantitative recording of rotational behavior in rats after 6-hydroxydopamine lesions of the nigrostriatal dopamine system. Brain Res. (1970) doi:10.1016/00068993(70)90187-3.

27. Machado, R. B., Tufik, S. \& Suchecki, D. Chronic stress during paradoxical sleep deprivation increases paradoxical sleep rebound: Association with prolactin plasma levels and brain serotonin content. Psychoneuroendocrinology 33, 1211-1224 (2008).

28. Panusa, A., Petrucci, R., Lavecchia, R. \& Zuorro, A. UHPLC-PDA-ESI-TOF/MS metabolic profiling and antioxidant capacity of arabica and robusta coffee silverskin: Antioxidants vs phytotoxins. Food Res. Int. 99, 155-165 (2017).

29. Costa, J., Lunet, N., Santos, C., Santos, J. \& Vaz-Carneiro, A. Caffeine exposure and the risk of Parkinson's disease: A systematic review and meta-analysis of observational studiess. J. Alzheimer's Dis. 20, (2010).

30. Chen, J. F. et al. Neuroprotection by caffeine and A(2A) adenosine receptor inactivation in a model of Parkinson's disease. J. Neurosci. 21, 2-7 (2001).

31. Xu, K., Xu, Y. H., Chen, J. F. \& Schwarzschild, M. A. Neuroprotection by caffeine: Time course and role of its metabolites in the MPTP model of Parkinson's disease. Neuroscience (2010) doi:10.1016/j.neuroscience.2010.02.020.

32. Machado-Filho, J. A. et al. Caffeine neuroprotective effects on 6-OHDA-lesioned rats are mediated by several factors, including pro-inflammatory cytokines and histone deacetylase inhibitions. Behav. Brain Res. 264, 116-125 (2014).

33. Luan, Y. et al. Chronic caffeine treatment protects against a-synucleinopathy by reestablishing autophagy activity in the mouse striatum. Front. Neurosci. 12, (2018). 
34. Mancini, R. S., Wang, Y. \& Weaver, D. F. Phenylindanes in brewed coffee inhibit amyloid-beta and tau aggregation. Front. Neurosci. 12, 1-14 (2018).

35. Di Matteo, V. \& Esposito, E. Biochemical and therapeutic effects of antioxidants in the treatment of Alzheimer's disease, Parkinson's disease, and amyotrophic lateral sclerosis. Current drug targets. CNS and neurological disorders (2003) doi:10.2174/1568007033482959.

36. Pohl, F. \& Lin, P. K. T. The potential use of plant natural products and plant extracts with antioxidant properties for the prevention/treatment of neurodegenerative diseases: In vitro, in vivo and clinical trials. Molecules 23, (2018).

37. Chu, Y. F. et al. Roasted coffees high in lipophilic antioxidants and chlorogenic acid lactones are more neuroprotective than green coffees. J. Agric. Food Chem. 57, 9801-9808 (2009).

38. Daglia, M., Papetti, A., Gregotti, C., Bertè, F. \& Gazzani, G. In vitro antioxidant and ex vivo protective activities of green and roasted coffee. J. Agric. Food Chem. 48, 1449-1454 (2000).

39. Moo-Puc, R. E. et al. Caffeine and muscarinic antagonists act in synergy to inhibit haloperidolinduced catalepsy. Neuropharmacology 45, 493-503 (2003).

40. Góngora-Alfaro, J. L. et al. Long-lasting resistance to haloperidol-induced catalepsy in male rats chronically treated with caffeine. Neurosci. Lett. 463, 210-214 (2009).

41. Malec, D. Haloperidol-induced catalepsy is influenced by adenosine receptor antagonists. Pol. J. Pharmacol. (1997).

42. Teraoka, M. et al. Cytoprotective effect of chlorogenic acid against a-synuclein-related toxicity in catecholaminergic PC12 cells. J. Clin. Biochem. Nutr. (2012) doi:10.3164/jcbn.D-11-00030.

43. Lee, K. W. et al. Neuroprotective and Anti-inflammatory Properties of a Coffee Component in the MPTP Model of Parkinson's Disease. Neurotherapeutics 10, 143-153 (2013).

44. Yan, R. et al. Synergistic neuroprotection by coffee components eicosanoyl-5-hydroxytryptamide and caffeine in models of Parkinson's disease and DLB. Proc. Natl. Acad. Sci. U. S. A. (2018) doi:10.1073/pnas.1813365115.

45. Schwarting, R. K. W. \& Huston, J. P. Unilateral 6-hydroxydopamine lesions of meso-striatal dopamine neurons and their physiological sequelae. Prog. Neurobiol. (1996) doi:10.1016/S03010082(96)00015-9.

46. lancu, R., Mohapel, P., Brundin, P. \& Paul, G. Behavioral characterization of a unilateral 6-OHDA-lesion model of Parkinson's disease in mice. Behav. Brain Res. (2005) doi:10.1016/j.bbr.2005.02.023.

47. Yuan, H., Sarre, S., Ebinger, G. \& Michotte, Y. Histological, behavioural and neurochemical evaluation of medial forebrain bundle and striatal 6-OHDA lesions as rat models of Parkinson's disease. $J$. Neurosci. Methods (2005) doi:10.1016/j.jneumeth.2004.10.004.

48. Lane, E. L., Cheetham, S. C. \& Jenner, P. Does contraversive circling in the 6-OHDA-lesioned rat indicate an ability to induce motor complications as well as therapeutic effects in Parkinson's disease? Exp. Neurol. 197, 284-290 (2006). 
49. Cauli, O., Pinna, A., Valentini, V. \& Morelli, M. Subchronic caffeine exposure induces sensitization to caffeine and cross-sensitization to amphetamine ipsilateral turning behavior independent from dopamine release. Neuropsychopharmacology 28, 1752-1759 (2003).

50. Aguiar, L. M. V. et al. Neuroprotective effects of caffeine in the model of 6-hydroxydopamine lesion in rats. Pharmacol. Biochem. Behav. 84, 415-419 (2006).

51. Bové, J. et al. Neuroprotection induced by the adenosine A2A antagonist CSC in the 6-OHDA rat model of parkinsonism: Effect on the activity of striatal output pathways. Exp. Brain Res. 165, 362374 (2005).

52. Kachroo, A., Irizarry, M. C. \& Schwarzschild, M. A. Caffeine protects against combined paraquat and maneb-induced dopaminergic neuron degeneration. Exp. Neurol. 223, 657-661 (2010).

53. Tsai, S. J., Chao, C. Y. \& Yin, M. C. Preventive and therapeutic effects of caffeic acid against inflammatory injury in striatum of MPTP-treated mice. Eur. J. Pharmacol. (2011) doi:10.1016/j.ejphar.2011.09.171.

54. Cho, E. S. et al. Attenuation of oxidative neuronal cell death by coffee phenolic phytochemicals. Mutat. Res. - Fundam. Mol. Mech. Mutagen. 661, 18-24 (2009).

55. Lee, M., McGeer, E. G. \& McGeer, P. L. Quercetin, not caffeine, is a major neuroprotective component in coffee. Neurobiol. Aging 46, 113-123 (2016).

56. Deumens, R., Blokland, A. \& Prickaerts, J. Modeling Parkinson's disease in rats: An evaluation of 6OHDA lesions of the nigrostriatal pathway. Exp. Neurol. 175, 303-317 (2002).

\section{Tables}


Table 1

Monoamines dosage (HPLC) in the right and left striatum of animals with lesion in the right side of medial forebrain bundle (MFB) and in sham-operated animals. Data are expressed as mean \pm standard error of mean $(n=4-7)$

\begin{tabular}{|lllllll|}
\hline Treatment & \multicolumn{5}{c}{ Monoamines / metabolites (ng/mg protein) } \\
\hline (right side) & NE & DA & DOPAC & HVA & 5-HT & 5-HIAA \\
\hline Sham-operated & $8.66 \pm$ & $71.44 \pm$ & $15.16 \pm$ & $3.83 \pm$ & $9.89 \pm$ & $5.81 \pm$ \\
& 2.00 & 14.71 & 9.61 & 0.83 & 0.63 & 0.72 \\
\hline Vehicle & $5.49 \pm$ & $34.37 \pm$ & $4.30 \pm$ & $2.98 \pm$ & $12.55 \pm$ & $8.47 \pm$ \\
& 1.87 & 15.83 & 1.79 & 0.83 & 3.04 & 2.13 \\
\hline Caffeine & $7.54 \pm$ & $35.60 \pm$ & $4.12 \pm$ & $3.04 \pm$ & $11.83 \pm$ & $6.28 \pm$ \\
$31.2 \mathrm{mg} / \mathrm{kg}$ & 2.81 & 15.66 & 1.37 & 1.34 & 1.95 & 1.67 \\
\hline CE 100 mg/kg & $3.77 \pm$ & $32.84 \pm$ & $2.50 \pm$ & $1.88 \pm$ & $11.23 \pm$ & $13.90 \pm$ \\
& 0.32 & 15.26 & 0.89 & 0.67 & 0.83 & 6.00 \\
\hline CE 400 mg/kg & $3.16 \pm$ & $42.45 \pm$ & $3.88 \pm$ & $1.91 \pm$ & $11.27 \pm$ & $8.83 \pm$ \\
& 1.22 & 20.35 & 1.46 & 0.78 & 2.26 & 2.03 \\
\hline (left side) & NE & DA & DOPAC & HVA & $\mathbf{5 - H T}$ & $\mathbf{5 - H I A A}$ \\
\hline Sham-operated & $6.49 \pm$ & $57.76 \pm$ & $3.98 \pm$ & $1.49 \pm$ & $10.05 \pm$ & $5.25 \pm$ \\
& 1.35 & 13.80 & 0.88 & 0.48 & 1.72 & 1.04 \\
\hline Vehicle & $4.67 \pm$ & $62.18 \pm 7.33$ & $4.53 \pm$ & $2.01 \pm$ & $9.87 \pm$ & $5.97 \pm$ \\
& 0.86 & & 0.37 & 0.32 & 0.89 & 0.82 \\
\hline Caffeine & $6.00 \pm$ & $64.35 \pm$ & $5.70 \pm$ & $3.47 \pm$ & $12.15 \pm$ & $4.63 \pm$ \\
\hline $1.2 \mathrm{mg} / \mathrm{kg}$ & 1.97 & 18.26 & 1.50 & 1.51 & 2.90 & 1.77 \\
\hline CE 100 mg/kg & $4.95 \pm$ & $134.15 \pm$ & $8.09 \pm$ & $4.41 \pm$ & $9.87 \pm$ & $10.76 \pm$ \\
& 0.42 & 15.06 & 1.13 & 0.98 & 1.18 & 3.75 \\
\hline CE 400 mg/kg & $8.54 \pm$ & $80.46 \pm$ & $6.43 \pm$ & $3.46 \pm$ & $8.98 \pm$ & $6.54 \pm$ \\
& 3.14 & 24.89 & 2.10 & 0.91 & 2.07 & 1.75 \\
\hline Kruskal-Wallis (n.s.) & & & & & & \\
\hline
\end{tabular}


Table 2

Monoamines dosage (HPLC) in the right and left striatum of animals with lesion in the right side of striatum and in sham-operated animals. Data are expressed as mean \pm standard error of mean $(n=7-8)$

\begin{tabular}{|c|c|c|c|c|c|c|}
\hline Treatment & Monoamine & / metabolites & g/mg pro & & & \\
\hline (right side) & NE & DA & DOPAC & HVA & $5-\mathrm{HT}$ & 5-HIAA \\
\hline Sham-operated & $\begin{array}{l}30.97 \pm \\
14.09\end{array}$ & $\begin{array}{l}110.08 \pm \\
18.08\end{array}$ & $\begin{array}{l}20.08 \pm \\
6.78\end{array}$ & $\begin{array}{l}17.97 \pm \\
7.83\end{array}$ & $\begin{array}{l}21.72 \pm \\
7.64\end{array}$ & $\begin{array}{l}18.81 \pm \\
7.42\end{array}$ \\
\hline Vehicle & $\begin{array}{l}12.49 \pm \\
4.38\end{array}$ & $\begin{array}{l}65.29 \pm \\
13.69\end{array}$ & $\begin{array}{l}6.44 \pm \\
1.16\end{array}$ & $\begin{array}{l}4.85 \pm \\
0.82\end{array}$ & $\begin{array}{l}6.88 \pm \\
1.41\end{array}$ & $\begin{array}{l}5.30 \pm \\
1.14\end{array}$ \\
\hline $\begin{array}{l}\text { Caffeine } \\
31.2 \mathrm{mg} / \mathrm{kg}\end{array}$ & $\begin{array}{l}13.40 \pm \\
2.22\end{array}$ & $\begin{array}{l}54.76 \pm \\
16.61\end{array}$ & $\begin{array}{l}6.17 \pm \\
1.88\end{array}$ & $\begin{array}{l}4.68 \pm \\
1.27\end{array}$ & $\begin{array}{l}9.00 \pm \\
2.65\end{array}$ & $\begin{array}{l}6.02 \pm \\
1.76\end{array}$ \\
\hline CE $100 \mathrm{mg} / \mathrm{kg}$ & $8.79 \pm 3.01$ & $68.94 \pm 9.34$ & $\begin{array}{l}6.75 \pm \\
0.97\end{array}$ & $\begin{array}{l}4.38 \pm \\
0.97\end{array}$ & $\begin{array}{l}7.79 \pm \\
0.88\end{array}$ & $\begin{array}{l}4.80 \pm \\
1.12\end{array}$ \\
\hline CE $400 \mathrm{mg} / \mathrm{kg}$ & $\begin{array}{l}16.94 \pm \\
9.82\end{array}$ & $\begin{array}{l}72.13 \pm \\
17.47\end{array}$ & $\begin{array}{l}10.20 \pm \\
5.86\end{array}$ & $\begin{array}{l}9.32 \pm \\
6.79\end{array}$ & $\begin{array}{l}13.27 \pm \\
5.77\end{array}$ & $\begin{array}{l}9.69 \pm \\
5.71\end{array}$ \\
\hline (left side) & NE & DA & DOPAC & HVA & 5-HT & 5-HIAA \\
\hline Sham-operated & $\begin{array}{l}11.66 \pm \\
2.89\end{array}$ & $\begin{array}{l}79.32 \pm \\
18.32\end{array}$ & $\begin{array}{l}7.28 \pm \\
1.51\end{array}$ & $\begin{array}{l}3.37 \pm \\
1.15\end{array}$ & $\begin{array}{l}7.06 \pm \\
1.15\end{array}$ & $\begin{array}{l}4.50 \pm \\
1.17\end{array}$ \\
\hline Vehicle & $5.71 \pm 1.18$ & $\begin{array}{l}71.90 \pm \\
16.76\end{array}$ & $\begin{array}{l}5.91 \pm \\
1.57\end{array}$ & $\begin{array}{l}2.51 \pm \\
0.86\end{array}$ & $\begin{array}{l}4.92 \pm \\
1.32\end{array}$ & $\begin{array}{l}3.71 \pm \\
1.04\end{array}$ \\
\hline $\begin{array}{l}\text { Caffeine } \\
31.2 \mathrm{mg} / \mathrm{kg}\end{array}$ & $\begin{array}{l}12.31 \pm \\
2.28\end{array}$ & $\begin{array}{l}59.74 \pm \\
20.98\end{array}$ & $\begin{array}{l}4.58 \pm \\
1.78\end{array}$ & $\begin{array}{l}2.28 \pm \\
0.84\end{array}$ & $\begin{array}{l}7.09 \pm \\
1.69\end{array}$ & $\begin{array}{l}5.71 \pm \\
1.88\end{array}$ \\
\hline CE $100 \mathrm{mg} / \mathrm{kg}$ & $6.49 \pm 1.57$ & $\begin{array}{l}79.50 \pm \\
15.75\end{array}$ & $\begin{array}{l}7.94 \pm \\
1.93\end{array}$ & $\begin{array}{l}4.33 \pm \\
1.04\end{array}$ & $\begin{array}{l}9.26 \pm \\
1.17\end{array}$ & $\begin{array}{l}5.35 \pm \\
1.23\end{array}$ \\
\hline CE $400 \mathrm{mg} / \mathrm{kg}$ & $\begin{array}{l}15.91 \pm \\
9.50\end{array}$ & $\begin{array}{l}59.07 \pm \\
12.63\end{array}$ & $\begin{array}{l}3.69 \pm \\
0.79\end{array}$ & $\begin{array}{l}1.08 \pm \\
0.37\end{array}$ & $\begin{array}{l}6.12 \pm \\
1.07\end{array}$ & $\begin{array}{l}2.77 \pm \\
0.80\end{array}$ \\
\hline
\end{tabular}

Kruskal-Wallis (n.s)

Figures 
Experiment 1A

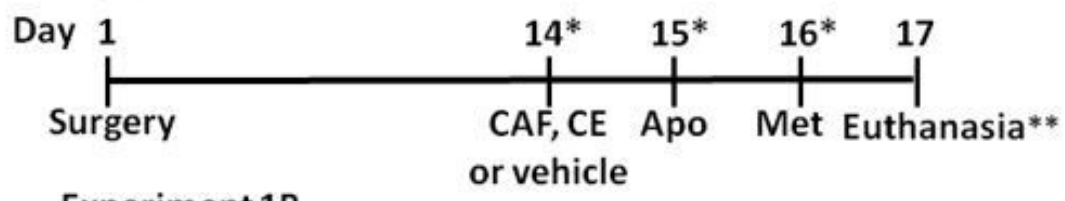

Experiment 1B
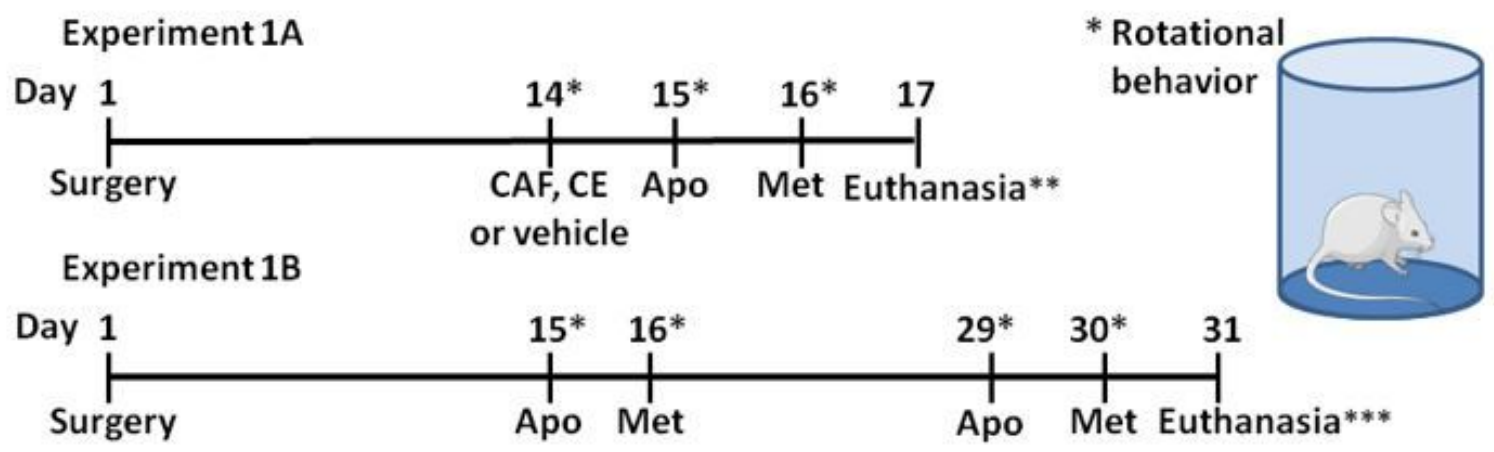

Treatment with CAF, CE or vehicle

\section{Experiment 2}
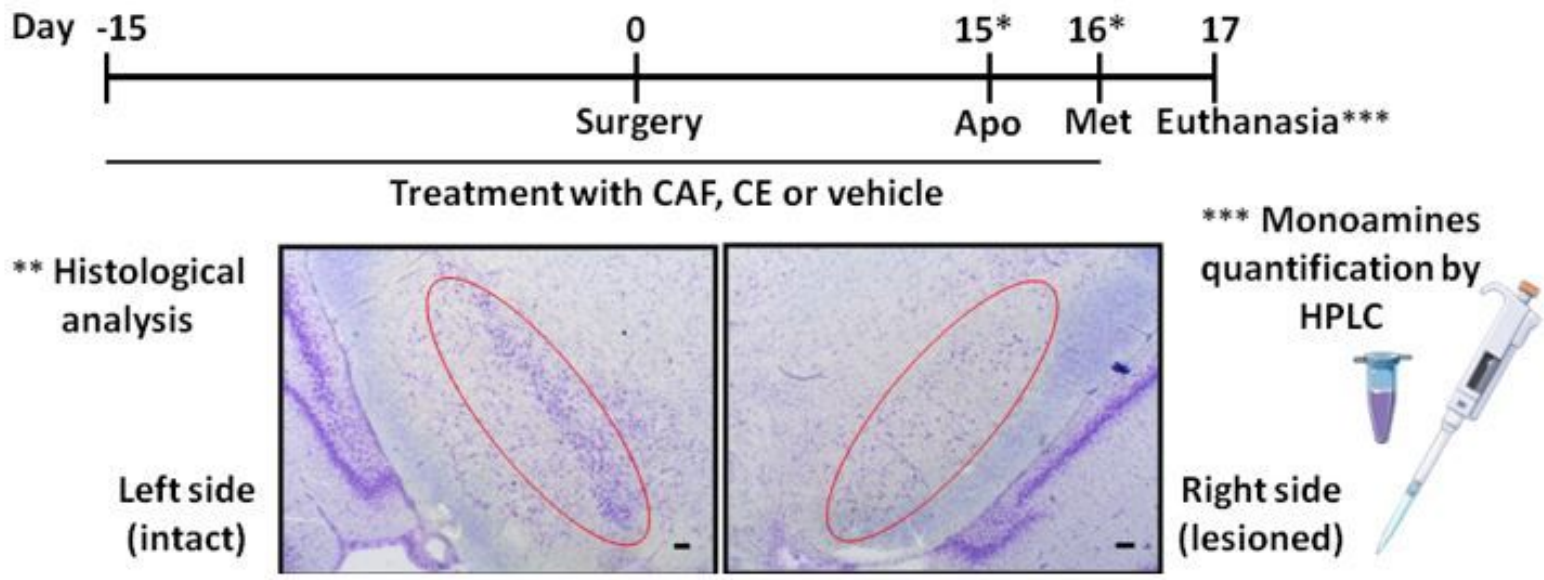

Figure 1

Schematic representation of the experimental design for the 6-OHDA unilateral lesion model. Experiments $1 \mathrm{~A}$ and 1B: lesion on medial forebrain bundle (MFB); experiment 2: lesion on striatum. $\mathrm{CE}=$ coffee extract, $\mathrm{CAF}=$ caffeine, $\mathrm{APO}=$ apomorphine, $\mathrm{MET}=$ methamphetamine . 


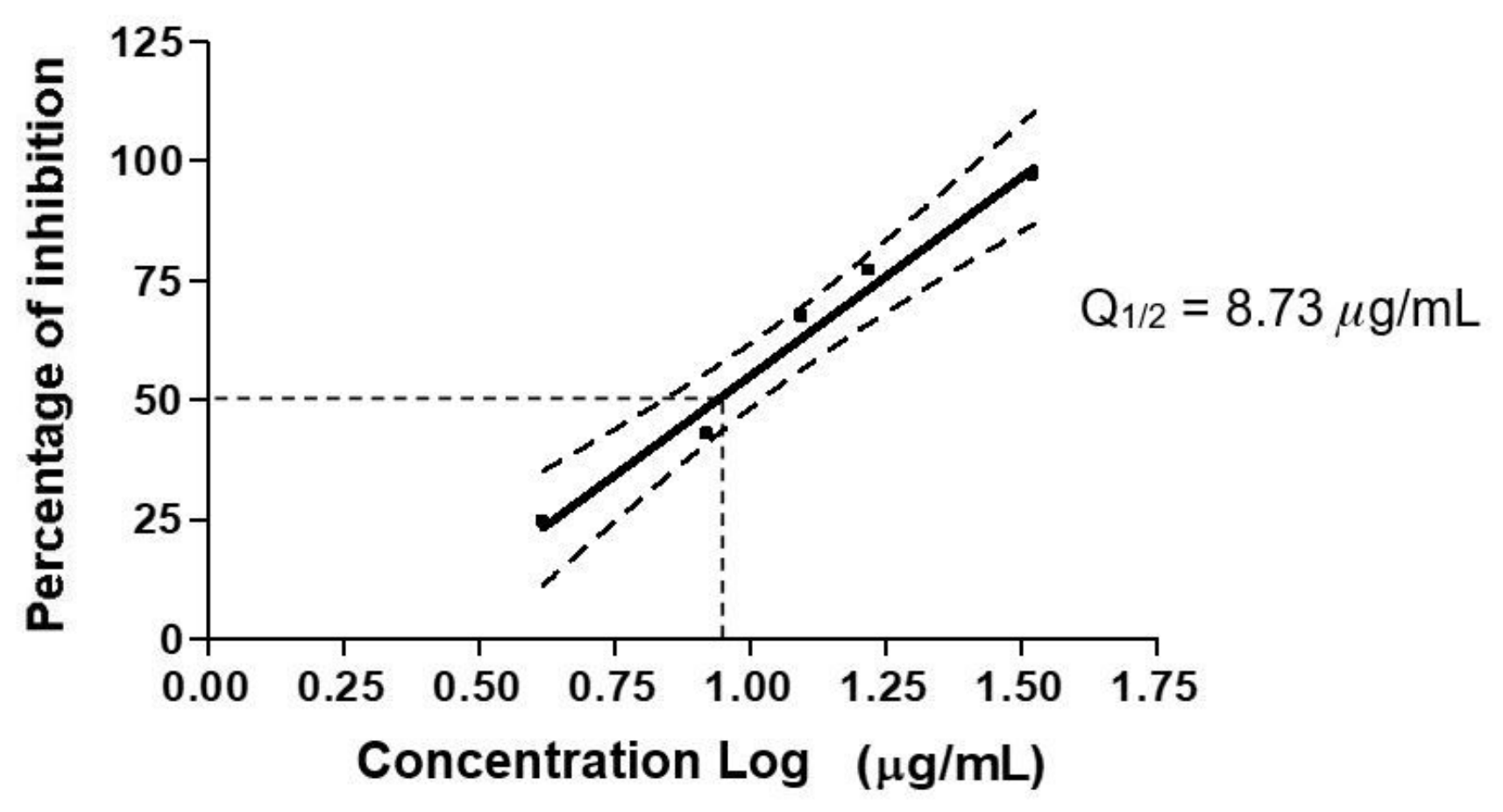

Figure 2

Linear regression to determine the percentage of inhibition of spontaneous lipid peroxidation in homogenate of the rat brain by coffee extract (CE). The dotted curves indicate the $95 \%$ confidence interval. The Q1/2 was calculated as $8.73 \mu \mathrm{g} / \mathrm{mL}$ ( $\mathrm{n}=4$ assays). 
$\square$ Negative control
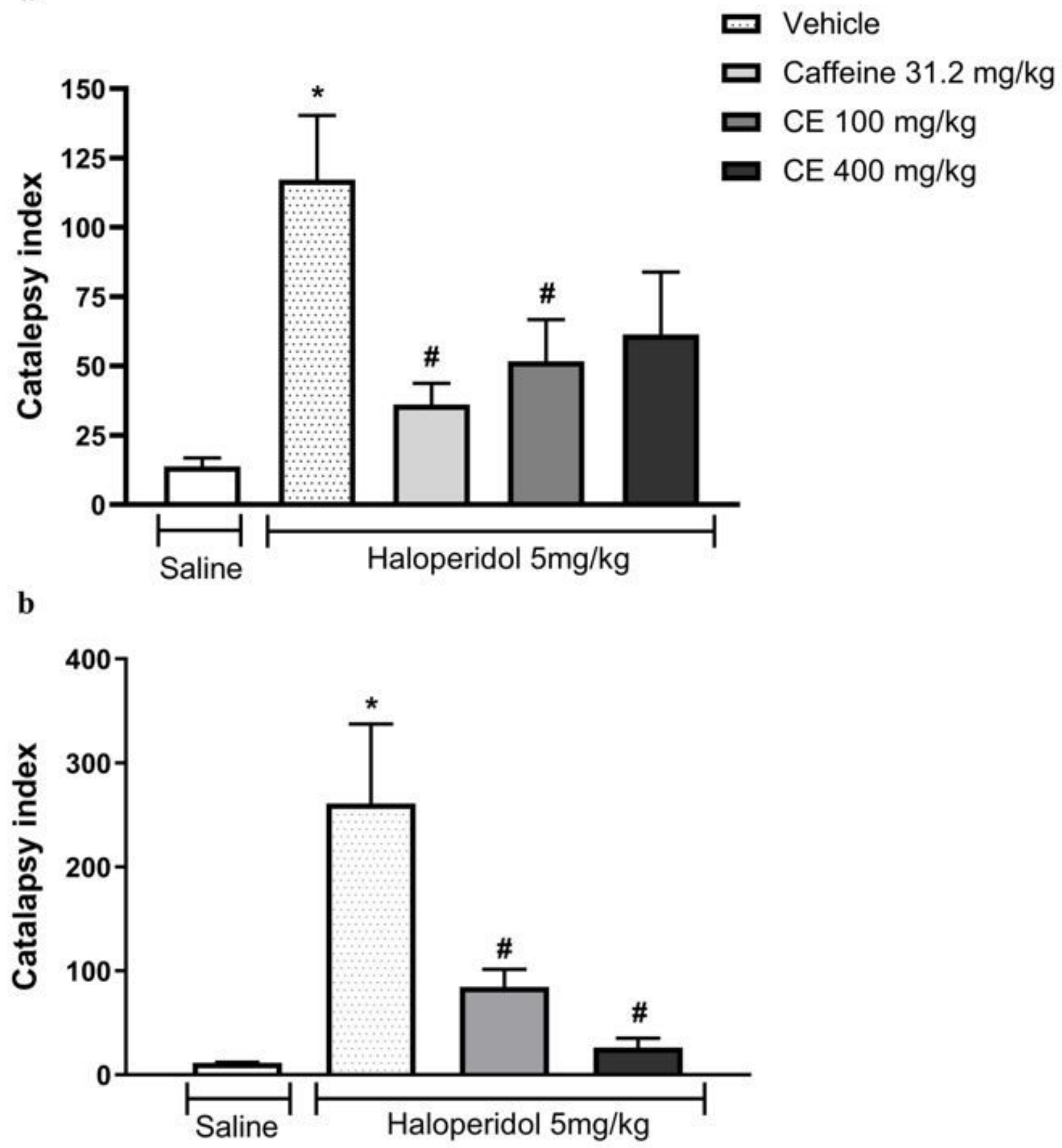

Figure 3

Blocked of catalepsy induced by haloperidol ( $5 \mathrm{mg} / \mathrm{kg}$, ip) after acute (a) or repeated (b) treatment (15 days) with coffee extract (CE 100 or $400 \mathrm{mg} / \mathrm{kg}$, po) or caffeine $(31.2 \mathrm{mg} / \mathrm{kg}$, po). Caffeine effect was evaluated only after acute treatment. Catalepsy index (catalepsy time/number of times the mouse went down the bar). Data are expressed as mean \pm standard error of mean, $n=6-13$. ${ }^{*} p<0.05$ statistically 
different from negative control group; $\# p<0.05$ statistically different from haloperidol-vehicle control (ANOVA followed by Tukey).

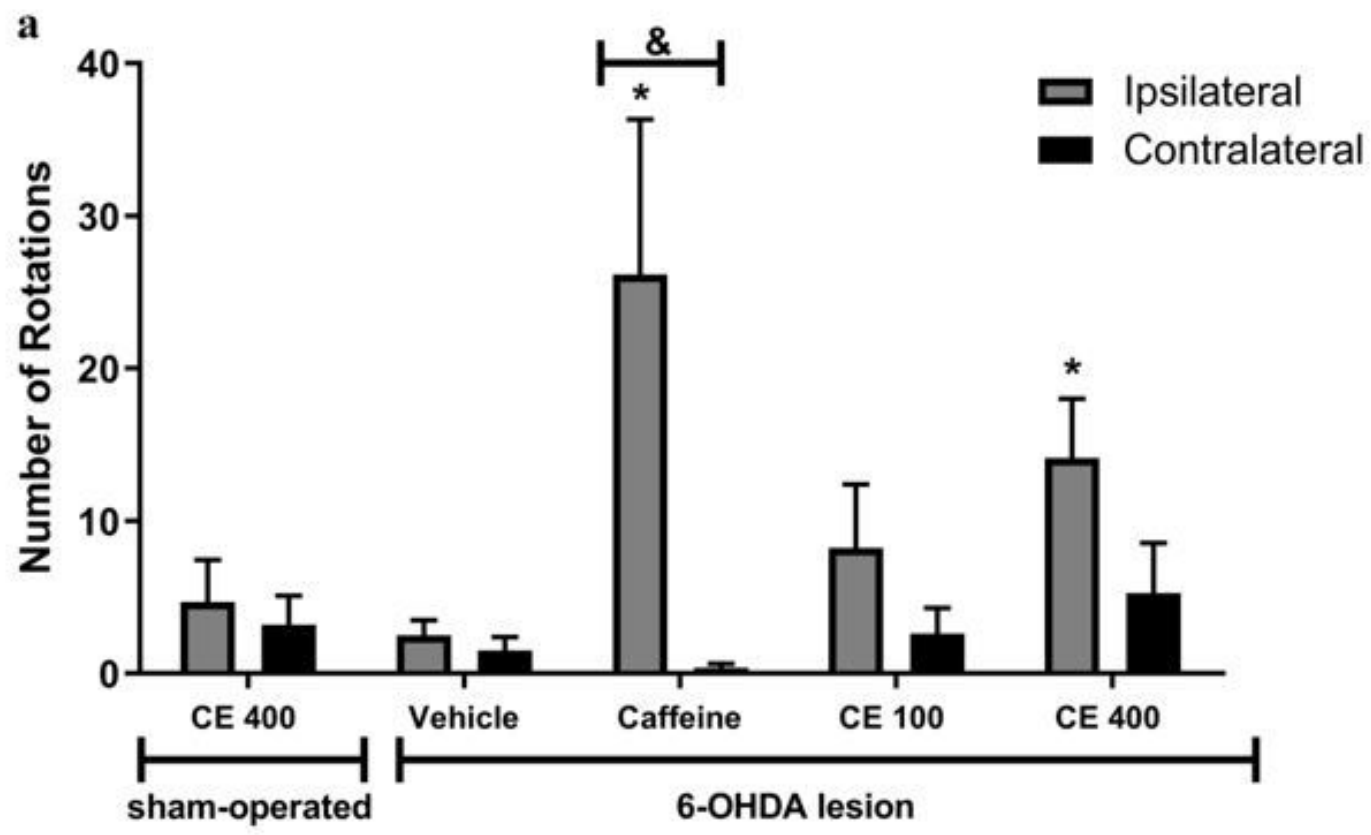

b

c
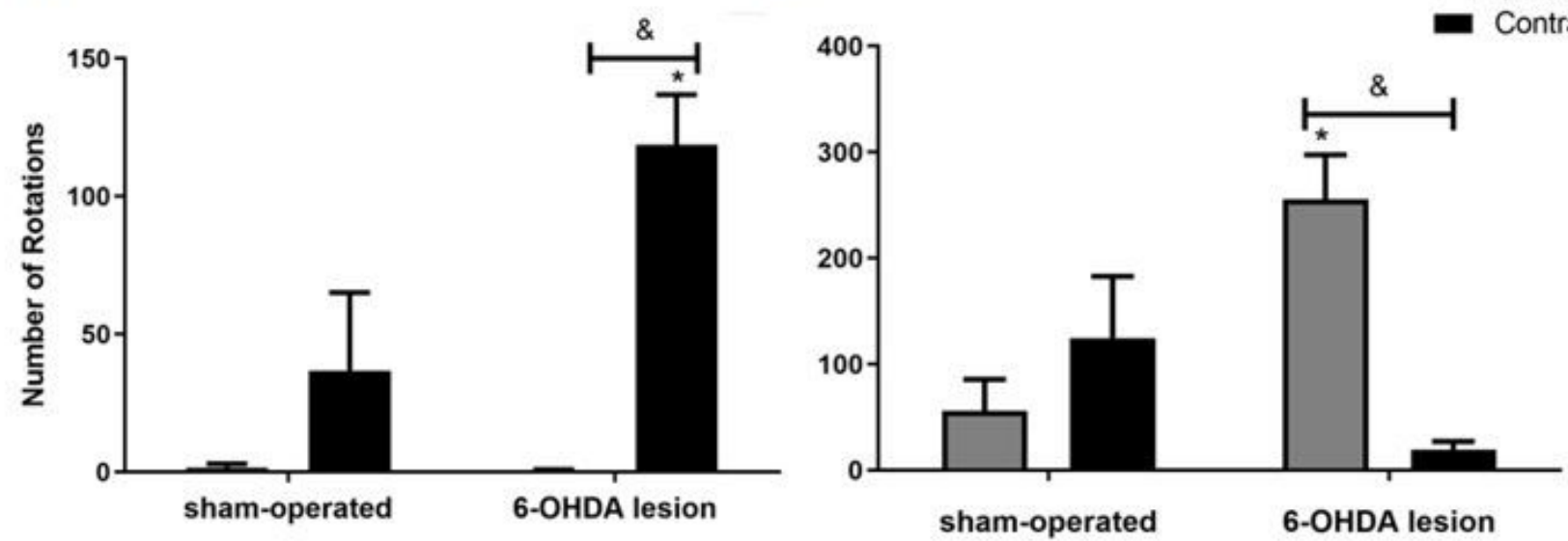

Figure 4

Rotational behavior in rats with 6-OHDA unilateral lesion of medial forebrain bundle (MFB). a) 14th day challenged with coffee extract (CE 100 or $400 \mathrm{mg} / \mathrm{kg}$, po), caffeine (31.2 mg/kg, po) or vehicle. b) 15th day challenged with apomorphine $(0.1 \mathrm{mg} / \mathrm{kg}, \mathrm{sc})$. c) 16th day challenged with methamphetamine (2.5 $\mathrm{mg} / \mathrm{kg}$, ip). Data are expressed as mean \pm standard error of mean, $n=10-15 .{ }^{*} p<0.05$ statistically different from vehicle (Kruskall-Wallis/Mann-Whitney, panel a) or sham-operated group (Mann-Whitney, panels b and c); \& $<0.05$ statistically different when comparing ipsilateral vs contralateral (intra-group comparison, Wilcoxon). 
a

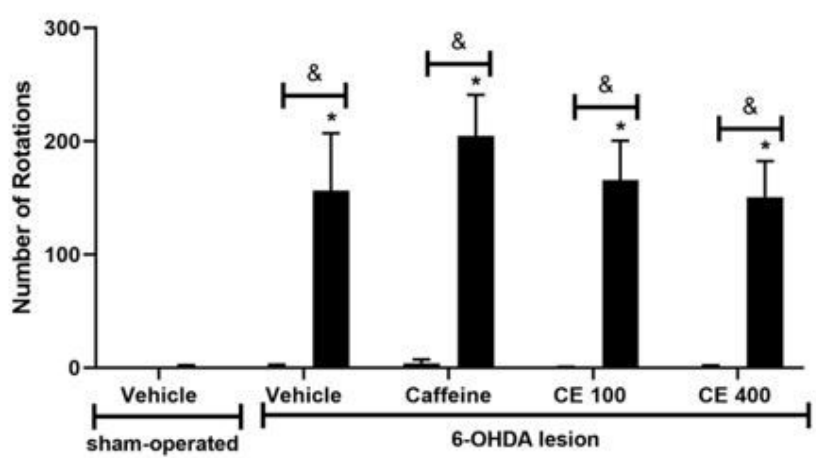

c

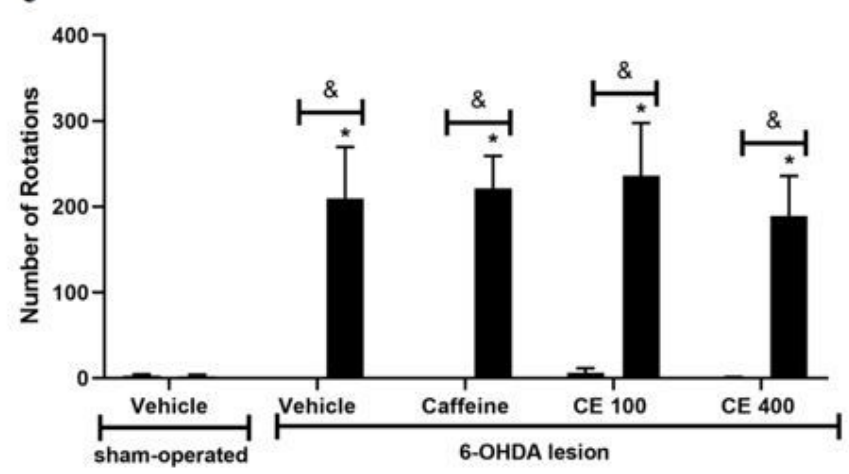

b

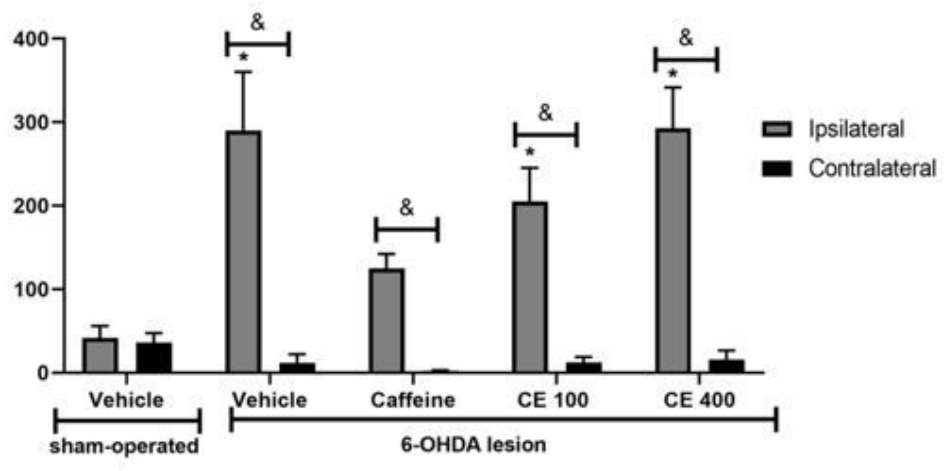

d

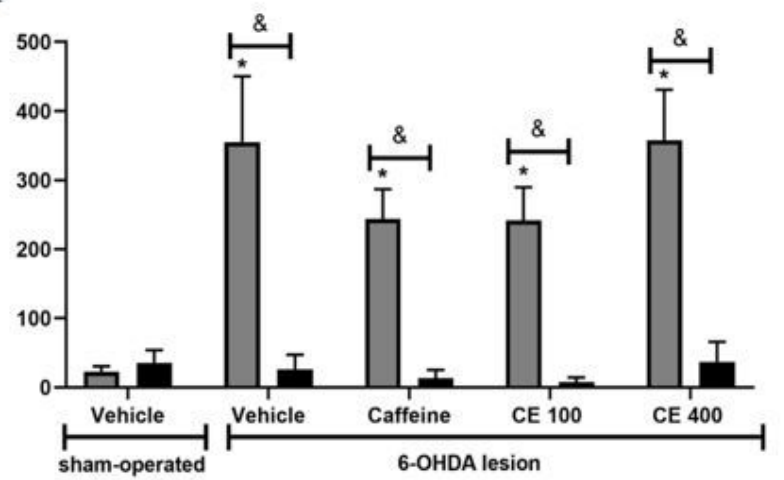

Figure 5

Rotational behavior of rats with 6-OHDA unilateral lesion of medial forebrain bundle (MFB) observed for 60 min after apomorphine challenge in the15th (a) and 29th (c) days $(0.1 \mathrm{mg} / \mathrm{kg}, \mathrm{sc})$ and methamphetamine challenge 16th (b) and 30rd (d) days (2.5 mg/kg, ip). Data are expressed as mean \pm standard error of mean, $n=12-15$. ${ }^{*}<<0.05$ statistically different from sham-operated group (KruskallWallis/Mann-Whitney). \&p<0.05 statistically different when comparing ipsilateral vs contralateral (intragroup comparison, Wilcoxon). 


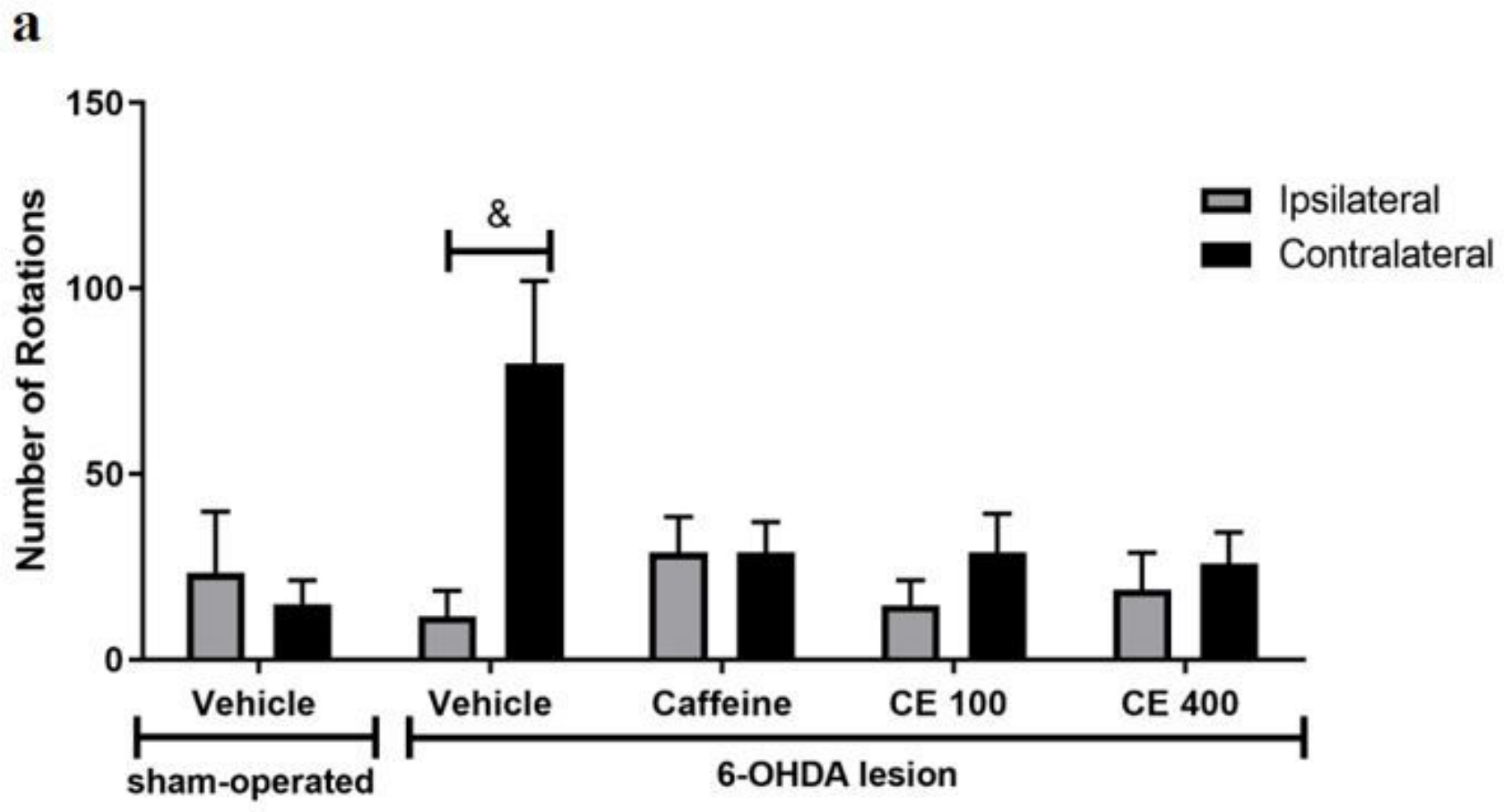

b

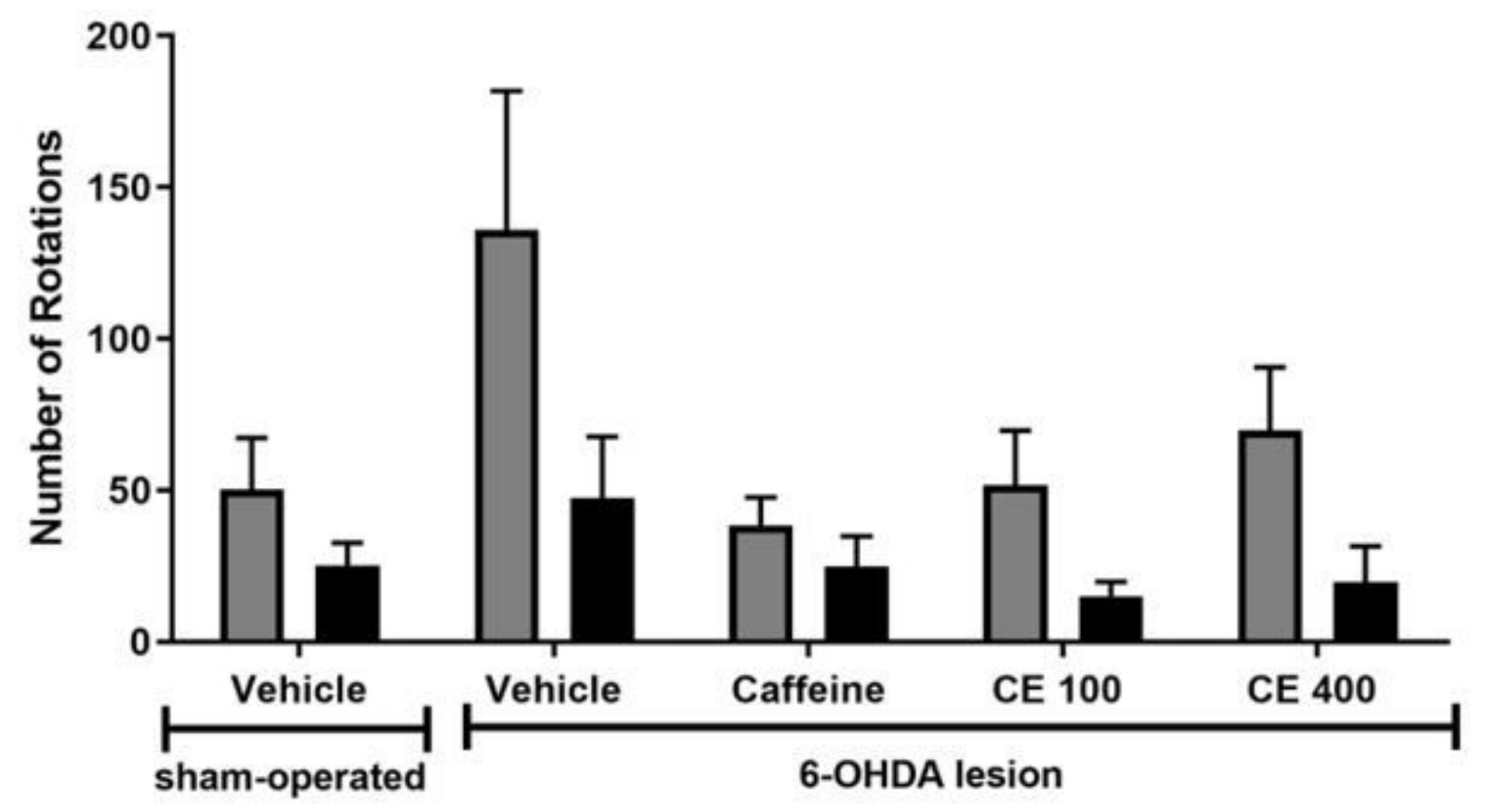

Figure 6

Rotational behavior of rats with 6-OHDA unilateral lesion of striatum. a) Apomorphine challenge (15th day) and $b$ ) Methamphetamine challenge (16th day). Data are expressed as mean \pm standard error of mean, $n=11-15$. Kruskal-Wallis $p>0.05$, n.s. (inter-group comparisons); \& $<0.05$ statistically different when comparing ipsilateral vs contralateral (intra-group comparison, Wilcoxon). 


\section{Supplementary Files}

This is a list of supplementary files associated with this preprint. Click to download.

- SupplementarydataS1.xlsx

- SupplementarydataS2.docx 